\title{
Neuropsychiatric complications of hyperacute transplant rejection: A psychiatrist-patient's experience and a brief literature review.
}

\author{
Complicaciones neuropsiquiátricas causadas por rechazo agudo de transplante de órgano: Experiencias \\ de un paciente-psiquiatra.
}

Moises Gaviria', Renato D. Alarcón², Nancy Gaviria³

\section{SUMMARY}

In this clinical case, the patient (a psychiatrist and one of the authors) experienced a variety of hyperacute medical and neuro-psychiatric complications after kidney transplant rejection. The patient's personal reflections and observations, communications with his wife, descriptions of clinical and experiential events, and medical interventions at different stages of the process are presented. Literature on the phenomenology of these complications and the bio-psycho-socio-cultural factors at play are reviewed. The unique perception of the psychiatrist's own experience lends support to recommendations regarding roles of different discipline members of the transplant team, and procedures for adequate clinical management of kidney transplant rejection.(Rev Neuropsiquiatr 2009; 72:67-74).

KEY WORDS: Kidney transplant rejection, delirium, immunosuppression, patient role.

\begin{abstract}
RESUMEN
El paciente cuyo caso se examina en esta presentación, médico psiquiatra y uno de los autores del articulo, experimentó una variedad de complicaciones médicas y neuropsiquiátricas agudas luego de ser sometido a cirugía de trasplante de riñón. Sus reflexiones y observaciones personales, así como su descripción de eventos clínicos y experienciales, intervenciones médicas en diferentes estadíos del proceso y la estrecha comunicación verbal y escrita con su esposa son materia de comentario y análisis. Se revisa la literatura en torno a la fenomenología de estas complicaciones y a los factores bio-psico-socio-culturales en juego. La singular percepción de estas experiencias por parte del psiquiatra como paciente respaldan una serie de sugerencias y recomendaciones en relación al papel de diferentes profesionales miembros del equipo de trasplante y a procedimientos destinados a un adecuado manejo clínico de las manifestaciones de rechazo de órganos trasplantados.(Rev Neuropsiquiatr 2009; 72:67-74).
\end{abstract}

PALABRAS CLAVE: Rechazo de trasplante de riñón, delirio, inmunosupresión, rol del paciente.

1 Distinguished Professor of Psychiatry at the University of Illinois at Chicago. Director of Neuropsychiatric Division at Advocate Christ Medical Center, Chicago, Illinois,USA.

2 Professor of Psychiatry, Mayo Clinic College of Medicine; Medical Director, Mood Disorder Unit, Mayo Psychiatry and Psychology Treatment Center, Rochester, MN. Titular de la Cátedra Honorio Delgado, Universidad Peruana Cayetano Heredia, Lima, Perú.

3 Occupational Therapist, Weiss Memorial Hospital. Gero-Psychiatric Unit, Chicago, Illinois,USA. 


\section{INTRODUCTION}

Kidney transplant has become the treatment of choice for patients with chronic renal failure from different etiologies, aimed at preventing the more time consuming and risk-laden dialysis procedure. Over the years, improved surgical techniques, preoperative and postoperative interventions, increasing public and patient education, and continuous technological progress have contributed to optimistic confirmations of the treatment's benefits and advantages (1-3).

Nevertheless, the procedure is not free of difficulties. The increasing number of patients in need of kidney transplant has created both logistic and clinical problems. The process of identifying, finding, selecting, and using potential donors has become more complicated and prolonged (4). At the present time, the centralized list of patients expecting or looking for donors in the U.S. may result in a four- or five-year waiting period. The rising hopes and shattered expectations of patients and their families and the clinical course of the primary renal problem itself may create, at times, dramatic situations. Furthermore, the procedure itself generates significant technical, clinical, and emotional challenges. The possibility of infections, surgical complications, immunosuppressive adverse effects and drug interactions, exposure to a complex regimen of medical care coordinated by a large multidisciplinary team are but a few of the complicating factors and potential sources of a less than favorable outcome $(5,6)$.

Organ rejection is a well recognized risk of transplantation with close monitoring required in the early post-operative period (7-9). The most serious phase is the first 48-72 hours after transplant, but the first three post-transplant months are critical. The acute (or hyperacute) kidney failure occurring immediately after the transplant, known as "initial never-functional transplant" (10), ends almost always with loss of the transplanted organs. Some statistics show that $10 \%$ to $15 \%$ of cases experience this complication (11). From an immunologic standpoint, the hyperacute rejection is the result of a massive production of pre-formed antibodies. Theoretically, this should be the least frequent cause, considering all the established rules and procedures for the evaluation of antibodies from both donor and recipient (12-14).

This article presents and discusses the clinical case of hyperacute kidney rejection experienced by one of the authors (M.G.). A variety of medical and neuropsychiatric complications were noticed, recorded, and examined both while they occurred and during the immediate post-acute phase. The actual procedure took place in a private health facility of a developing country, which added risk factors of a technical, psychological, and sociocultural nature. Observations on team structure, clinical interventions at different stages of the acute process, and interactions between team members are noted. The article concludes with comments on the roles of different disciplines and specialties, clinical management, and future perspectives for the field.

\section{Case report}

\section{History of present illness}

The patient is a 62-year-old Latin American psychiatrist working in a U.S. midwestern academic and clinical medical center for over 30 years. He had been diagnosed with glomerulosclerosis at the age of 32, after a renal biopsy. Throughout the years, he had well-controlled hypertension. For the last two years his kidney function was reduced to around 20 percent, and the creatinine level started to increase as the glomerular function declined to 10 percent. One year before surgery (around January 2005) the kidney follow-up team advised the patient to consider either transplant or dialysis.

After being referred to a transplant team, seeking a living donor became a rather frustrating experience. Two potential donors were found to be non-acceptable. Communication between clinicians (nephrologists) and surgeons (transplant team) was not consistent, actually at times plainly nonexistent. The same applied to interactions between two sub-teams within the transplant group, one dealing with the potential donor, and the other with the recipient, as both applied the concept of confidentiality in a different manner, generating disillusionment among the potential donors, and frustration for the patient and his family. In July 2005, the patient went to his country of birth, and found a potential donor a distant relative, willing to donate a kidney. The American team initially discarded this option, but accepted it five months later. However, a letter from the American Embassy in the Latin American country rejected the request of a humanitarian visa for the potential donor. As the patient's kidney function continued to deteriorate to below 10 percent, the rising creatinine level to $5.6 \mathrm{mg} / \mathrm{dL}$, BUN to $120 \mathrm{mg} / \mathrm{dL}$, and 
concomitant changes in potassium, phosphorus, and calcium levels intensified the search for a kidney transplant. The patient and his family decided to have the operation performed by a team with a good track record in his native country. His medication regimen at this point included Corgard, $240 \mathrm{mg}$ daily; Allopurinol, $100 \mathrm{mg}$ daily (for gout); Monopril, $40 \mathrm{mg}$ daily; Lipitor, $40 \mathrm{mg}$ daily; aspirin, $81 \mathrm{mg}$ daily; amitriptyline $25 \mathrm{mg}$ q.h.s.; and Clonazepam 0.5-1.0 mg q.h.s. for insomnia. He also had sleep apnea managed with a CPAP machine. Pre-transplant cardiovascular and blood tests were within normal limits.

\section{Surgery and Postoperative Clinical Course}

The patient was hospitalized the first week of february 2006, one day before the surgery. Aspirin had been discontinued two weeks before admission; all remaining medications were stopped on admission. Surgery apparently went well, but hemorrhages of small pelvic and abdominal capillary vessels within the first 24 hours post-surgery brought the hemoglobin level down to $8.0 \mathrm{~g} / \mathrm{dL}$. Hematomas in the affected areas, and one in the newly transplanted kidney were detected. A blood transfusion (2 units) was ordered, and the assumption was that the new kidney was "not functioning, but it would in a matter of time," so IV steroid immunosuppressors were started. Soon thereafter, the patient developed intermittent delirious symptoms. The patient's own recollections of this episode were recorded during his recovery, as follows:

First, I thought that all the nurses were from India, and I was wondering why I was in the clinic. As the delirium continued, I started to misidentify the nurses with my wife, and was absolutely irritated each time a nurse approached me. I thought it was my wife, just to find that it was not. I told the team that this was the effect of steroids, but they did not pay any attention. Finally, I became agitated and paranoid. I thought it was all a plot to kill me, and that they did not want me to leave the clinic alive. Later on, I was told by my wife that I had devised a plan to escape from the clinic, based on taking advantage of the nurses' change of shift time to do it. It was only four days later, when some psychiatrist friends of mine suggested the administration of haloperidol IM, that these delirious symptoms stopped.

Creatinine and BUN levels continued to be high during the first week post-surgery, and although the ultrasound was inconclusive, the transplant team chose to assume that the new kidney was functioning. At one point, a massive full-body edema developed. Shortly after the start of immunosuppressors, the patient presented leukocytosis and one day of fever. A suspicious $x$-ray of the lungs showed images compatible with infection, probably by Pneumocystis carinii, a complication about whose potentially fatal outcome the family was warned. However, antibiotic therapy, in combination with immunosuppressors and dialysis, controlled the infection after one week.

The uncertainty about the results of the kidney transplant remained throughout the patient's stay at the clinic until his return to the United States about three weeks after surgery. His sleep was extremely poor, and the concerns about infections in kidneys, liver, and other organs distracted the team from the fact that both clonazepam and amitriptyline (which the patient had taken for 20 years) had been abruptly withdrawn and never restarted.

\section{Recent Clinical Course}

On his return to the United States, the patient sought the opinion and care of a university hospital transplant team in his home city. On the day of admission, it was confirmed that the transplanted kidney was nonfunctional. Furthermore, pulmonary edema due to excessive administration of fluids was diagnosed. The electrolyte imbalance was corrected, surgery was performed to remove the nonfunctioning transplanted kidney, and a second surgery to create a fistula for future hemodialysis was performed. The pathological report of the transplanted kidney showed severe vascular rejection with transmural arteritis type 3 , massive thrombosis in the renal vessels, and extensive necrosis of renal parenchyma and portions of the ureter, with markedly active and chronic inflammation.

Severe body deconditioning was demonstrated by the patient's inability to walk one block without getting short of breath, severe constipation, erratic sleep, extreme weakness, and some cognitive difficulties, particularly memory for names. His mood showed significant variability, switching from irritability to hypersensitivity, occasional tearfulness, and negative comments regarding situations that in the past had not affected him. His sleep pattern was agitated for at least four more weeks. He had nightmares, night sweats, and subsequent tiredness. Active physical therapy, strict follow-up by the new transplant team, and close care by his wife led to complete recovery 
within about six weeks following his return. Memory problems disappeared, and his strength and stamina were back.

Current medications include atorvastatin, $20 \mathrm{mg}$ daily; aspirin, $81 \mathrm{mg}$ daily; metoprolol, $25 \mathrm{mg}$; furosemide, $40 \mathrm{mg}$ every morning for blood pressure control; amitryptyline $25 \mathrm{mg}$ at bedtime; and clonazepam $1.0 \mathrm{mg}$ at bedtime. Six months after his return, he started hemodialysis at the university outpatient dialysis center unit, while his name has been included in the long list for a cadaver donor. He is back at work on a full-time basis.

\section{DISCUSSION}

This clinical case covers a variety of aspects on the phenomenology of neuropsychiatric complications of hyperacute kidney transplant rejection, the different etio-pathogenic factors at play in the process, the physical and personal deconditioning problems, and subsequent psychological and interpersonal issues resulting from the surgery and the rejection itself. The patient's and his wife's professional background in the mental health field add a unique perspective to the report of these occurrences.

\section{Clinical symptoms}

In general, manifestations of transplant rejection include generalized body soreness, fever, hematuria, uremia, edema, occasional infections, and laboratory evidence of organ dysfunction. The patient had all of them. Trzepacz et al (15) group post-transplant clinical complications as surgical, medical, transplant organrelated, and neuropsychiatric. In this case, the latter include a delirious state with clearly psychotic and paranoid symptomatology (16). Delirium or delirious state presents a variety of clinical patterns. The patient may be fully alert at times, but on other occasions may behave automatically, seemingly in an active and even coherent manner, but keeping no memory or recollection of such behaviors, as indeed occurred in this case. This "in and out" process may be the result of different levels of toxicity, drug interactions, humoral mislevels, electrolyte imbalance, excess or scarcity of environmental cues (17), and repressed sensitivities and emotions.

Perez San Gregorio et al. (9) comment on the neglect of the psychological course of kidney transplant recipients after surgery. The clinical course may be changeable, and even in cases of less severe implications than the present one, higher levels of anxiety, depressive symptoms, sleep disruptions, and changes in body perceptions may be present in almost 50 percent of patients $(18)$. Fukunishi et al. $(7,19)$ mention that other than delirium, mood, adjustment, somatoform, anxiety, and brief psychotic disorders, whether or not associated with immunosuppressant toxicity, are very frequent. The same authors have coined the phrase "paradoxical psychiatric syndrome" that occurs despite a successful transplantation, and seems to be mostly related to the recipient's concerns about the donor's wellbeing. The authors associate this mixed psychiatric symptomatology with prominent intrapersonal or interpersonal conflict such as guilt, situational conflicts, or psychodynamic difficulties.

In our patient's case, the initial hemorrhage (occurring less than 24 hours after the transplant) contributed to a total and massive body deconditioning. The possible infection detected within the first week posttransplant, coupled with severe lack of sleep and subsequent nutritional deficits complicated matters even further. The result was the gradual emergence of cognitive problems, a paradoxical mix of distractibility, and intense focus on issues that were later incorporated into a consistent paranoid system. The patient's frustration was augmented as he perceived that nobody in the treatment team paid attention to his own observations and recommendations. The paranoid ideation had a logic of its own: the patient knew he was in a facility where he was supposed to get better but, as it was not the case, he made the professionals in charge responsible of his deterioration, and concluded that they did not want to him to leave the clinic alive, possibly because of the observations he had made during his moments of lucidity.

Consequently, making sure that his interactions with his wife were not being watched, he outlined a very careful escape plan that reflected accurate perceptions of realities such as shift changes, medication administration times, and interaction with staff members, but also showed the unrealistic assessment of other aspects of his reality at the time. Furthermore, in spite of memory and abstract thinking problems, the paranoid component did not involve his wife; on the contrary, he relied on her advice and company. On the other hand, he was not fully aware of the practical impossibility of carrying out the escape, as he was on continuous IV, intranasal oxygen, and other supportive devices. 
Self-image factors may have contributed to the cognitive phenomena as well as to the mood symptoms described; the full-body edema generated transfiguration of his self-body perceptions and functions. Emotional lability, irritability, anxiety, a sense of doom, loss, and possibly anticipated grief were more evident even weeks after the transplant surgery. Selfimage issues are closely related to so-called physical deconditioning (20), the massive decompensation resulting from humoral, tissular, and systemic changes taking place concurrently.

\section{Management issues}

Medication management might have contributed to the delirious/psychotic state following the hyperacute kidney transplant rejection. The treatment team glossed over the fact that the patient had been on benzodiazepines for almost 20 years to correct his sleep pattern. The acute withdrawal of benzodiazepines (no matter how small the dose,) and the lack of replacement or consideration of sleep problems during the days following surgery may have set the stage for the delirious state $(21,22)$, prompted by the administration of immunosuppressors, specifically corticosteroids. While a number of patients who receive IV steroids rapidly become manic or hypomanic (23), paranoid symptoms and, more importantly, cognitive imbalances have also been described (24-26). These adverse effects can sometimes last a long time $(15,27,28)$, and may occur as well with other commonly used immunosuppressive i.e. Tacrolimus, cyclosporine, and mycophenolate mofetil.

Continuous use of immunosuppressants is not advisable, but their discontinuation after renal transplant failure should be conducted very carefully (29) an abrupt withdrawal of immunosuppressants increases the risk of additional rejection symptoms. Furthermore, the withdrawal is not free of complications, including secondary adrenal insufficiency and potential immunologic consequences.

There are other types of transplant rejection based on the time following surgery. The so-called consolidating period goes from one to three months and may be mediated by cellular or humoral immunity problems or intercurrent interstitial nephritis (infection by bacteria and viruses); actually, a delayed interstitial nephritis (from the sixth to the ninth month), appears to be mostly related to polyomavirus and adenovirus $(30,31)$. Finally, the chronic period includes immunological (chronic rejection, vasculopathies, glomerulopathies), non-immunological (nephrotoxicity, ischemia, atherosclerosis, hyperfiltration), and recurrent or new diseases such as glomerulopathies (13).

Management of deconditioning is an important component of treatment in acute kidney transplant rejection (32). Rehabilitation medicine specialists do have a significant role in this area, aimed at helping in both the restoration of bodily functions and the elimination of ensuing body-image problems. In addition, extremely important psychological, emotional, interpersonal, and teamwork issues are worth considering. There is not much written about the role of psychological (or subjective) factors in the pathogenesis of hyperacute kidney transplant rejection. A common factor in all these issues may be the quality of the communication at different levels and its impact on the quality of the patient management. The clinical and surgical teams should carefully consider the sense of urgency, self-image issues, potential trust crises (with overdependent, ambivalent, and ultimately "paranoid" consequences) (33), and life/death expectations of the patient and his/her family $(7,15)$.

In this patient's case, the impact of his status as a professor from a major U. S. institution on the clinical and surgical team members of his native country was difficult to ascertain, despite its relevance (34). The staff members may have wanted to perform to the best of their abilities and provide the best possible care, generating increased stress in the process. Did denial -in the psychodynamic sense- of the severity of the rejection play a role in the subsequent management of the symptoms? Does the status of the recipient play a role in this aspect of care that could be called countertransferential?. Was not reinstituting sleep and antidepressant medication a result of denial, ignorance, hubris, or arrogance on the part of the treatment team? Issues like these deserve continuous attention by all members of transplant teams, and consultants from fields such as psychiatry, transplant psychology or bioethics. The routine use of diagnostic and management "checklists" on a daily (or even hourly) basis may be a pragmatic way to maintain appropriate communication among team members, patients and relatives, and prevent undesirable developments $(35,36)$.

Periodic procedural reviews and examination of "medical errors" should be part of systematic practices beyond medical school or specialty training processes. Recent institutional rules: medication reconciliation and 
similar procedures, enforced by regulatory agencies, can prevent omissions or neglect of medication administration (4).

\section{Other considerations}

Organ shortage and the subsequent unavailability has reached critical levels in the U.S., with very long waiting periods, inherent bureaucratic complexities and profound psychological suffering for patients and their families. This situation leads almost insensibly to a painful level of commercialization of organs, with offers proliferating even in internet sites; often, those who want to "donate" for variable amounts of money come from lower socio-economic levels, and many of them may not qualify due to general health, nutritional or other factors. The other side of this coin is the growing international nature of this commercial enterprise.

The second consequence of this may be the popularization of "transplant tourism", somewhat exemplified by the case discussed here. The long waiting period generates anguish and frustration that then leads the patient and his/her family to searches abroad, usually in the so-called underdeveloped countries where the economic urgencies of the population can increase the "supply" of potential donors (37). Furthermore, the U.S. may not allow entry to potential foreign donors (as was the case with our patient), and hospitals and clinics in those countries may have a decent transplant surgery record, so the "transplant tourism" comes full circle: the patient decides to have the (usually less expensive) operation performed in the country opening a "Pandora's box" of potential consequences for the recipients.

A little clinically explored aspect of this field of inquiry is the impact of a loss of a transplated organ on the organ's donor. Whether the donor is informed about the outcome does not seem to be known, much less his/her reaction to what can be literally considered "a waste". Does the fact that the donor is a family member or a total stranger influence this reaction?. Is this a particular kind of grief, deserving a better clinical configuration and description?. These are, certainly, valid questions in a field that due to a variety of factors will only grow in demographic and clinical importance for decades to come.

\section{CONCLUSIONS}

Transplant psychiatry has grown significantly and has acquired a relevant identity in the subspecialty field
$(34,38)$. Many programs, particularly in the Unites States and Europe, have developed specialized multidisciplinary mental health teams supporting practically every aspect of the transplant process, from identification of potential donors to psychological characteristics of donors and recipients, early interventions in pre- and post-transplant phases, and effective interventions in the case of psychiatric or neuropsychiatric complications. Prevention, early detection, and effective management of delirium and its eventual psychotic component should be a priority in these cases.

The use of checklists and regular case reviews (with mental health perspectives) is a valuable routine. The presence of a psychiatrist and other mental health professionals as prominent members of the transplant team entails a lot of potential advantages and benefits $(27,35)$. It can provide balance to the interpersonal perspective of the team who may be overtly influenced by bio-physiological and neuro physiological concepts and interventions. Efficient communication at all levels must be a decisive feature throughout all the steps of the transplant process. Staff members' correct perception of the history and characteristics of the recipient, and his or her individual, family and occupational characteristics, wold assure a more efficient and congenial approach to their heavy emotional investment and expectations.

The unique perspective of a psychiatrist experiencing the avatars of such a major procedure raises questions about self-perception, recollection, and even professional action beyond his "patient role" (38). The main purpose of this communication is to make professionals, patients, relatives, and public audiences aware of the unexpected and not so unexpected events, accidents, errors, or negative outcomes that may occur in the wake of kidney transplant.

\section{REFERENCES}

1. Gritish HA. Renal transplantation: Improving the quality of life (editorial). J Urol1996; 156:889.

2. Cameron JL, Whiteside C, Katz J, Devins CM. Differences in quality of life across renal replacement therapies: A meta-analytic comparison. Am J Kidney Dis 2000; 35:629-637.

3. Wolfe R, Asby VB, Mildford E, et al. Comparison of mortality in all patients of a first cadaveric transplant. N Eng J Med 1999; 341: 1725-1730.

4. National Kidney Foundation. 25 facts about organ donation and transplantation; 2007.

5. Goldfarb-Rumyantsev A, Hurdle J, Scandling J, 
et al.Duration of end stage renal disease and kidney transplant outcome. Nephrology Dialysis Transplantation 2005; 20: 167-175.

6. Webster A, Woodroffe R, Taylor R, Chapman J, Craig J. Tacrolimus versus ciclosporin as primary immunosuppression for kidney transplant recipients: Meta analysis and meta - regression of randomized trial data. Brit Med J 2005; 331: 810.

7. Fukunishi I, Sugawara Y, Takayama T, Makunchi K, Kawarasaki H, Surman OS. Psychiatric disorders before and after living-related transplantation. Psychosomatics 2001; 42: 337-343.

8. Haymann JP, Bedrossian J, Pruna A, Michaut P, Idatte JM. Cytomegalovirus (CMV) infection in kidneytransplant recipients-outcome of the renal function after one and three years follow up. J Amer Soc Nephrology 1994; 5: 1011.

9. Perez San Gregorio MA, Martin-Rodriguez A, GalanRodriguez A, Perez-Bernal J. Psychologic stages in renal transplant. Transplant Proc 2005; 37: 1449-1452.

10. Trpkovk , C., Pazderka, C., Solez, H. Pathological features of Allograft rejection associated with donor specific antibody: Analysis of Banff grading schema. Transplantation 1996; 61: 1586-1592.

11. Tinckan KJ, Chandraker A. Mechanisms and role of HLA and non HLA allo-antibodies in transplant rejection. Clin J Am Soc Nephrol 2006;1(3):404-414.

12. Bakir N, Sluiter WJ, Ploeg RJ, Van Son WJ, Tegzess AM. Primary renal graft thrombosis. Nephrol Dial Transplant 1996; 11: 140-147.

13. Perez-Fontan M, Rodriguez-Carmona A, Bousa P, et al. Outcome of grafts with long-lasting delayed function after renal transplantation. Transplantation 1996; 62: 42-47.

14. Vasquez Martul E, Veiga A. Biopsy of sub-optimal renal donors. Significance of the correct evaluation. Nefrologia 2002; 22: 1-3.

15. Trzepacz PT, Levenson JL, Tringali R. Psychopharmacology and neuropsychiatric syndromes in organ transplantation. Gen Hosp Psych 1991; 13: 233-245.

16. Dyrud JE. Post transplantation Delirium: A review. Current Opinion in Organ Transplantation 2004; 9: 428431.

17. Breitbart W, Gibson C, Tremblay A. The delirium experience: delirium recall and delirium-related distress in hospitalized patients with cancer, their spouses/ caregivers, and their nurses. Psychosomatics 2002; 43: 183-194.

18. Sabbatini M, Crispo A, Pisani A, et al. Sleep quality in renal transplant patients: A never investigated problem. Nephrol Dial Transplant 2005; 20:194-198.

19. Fukunishi I, Shindo M, Ohara T, et al. "Paradoxical depression” in living female donor after kidney transplantation. Psychosomatics 1998; 39: 396-397.
20. Hung J, Goldwater D, Convertino V, McKillop JH, Goris ML, De Busk RF. Mechanisms for decrease exercise capacity after bed rest in normal middle aged man. Am J Cardiol 1989; 51: 344-348.

21. Chouinard G. Issues in the clinical use of benzodiazepines: potency, withdrawal, and rebound. J Clin Psych 2004; 65(S5): 7-12.

22. Dial S, Payne J. Managing acute delirium in the intensive care unit. Clinical Pulmonary Med 2002; 9: 260-266.

23. Wada K, Yamada N, Sato T, et al. Corticosteroid-induced mood disorders. Psychosomatics 2001; 42: 461-466.

24. Davis JM, Leach A, Merk B, Janicak PG. Treatment of steroid psychoses. Psych Annals 1992; 22: 487-490.

25. Kershner P, Wang-Cheng R. Psychiatric side effects of steroid therapy. Psychosomatics 1989; 30: 135-139.

26.Reckart MD, Eisendrath SJ. Exogenous corticosteroid sffects on mood and cognition: case presentations. Int J Psychosom 1990; 37: 57-61.

27. Hall R, Popkin MK, Stickney SK, Gardner ER. Presentation of the steroid psychoses. J Nerv Ment Dis 1979; 167: 229-236.

28.Trzepacz PT, MartiniAD, Triangali R. Psychopharmacological issues in organ transplantation: Part I pharmacokinetics in organ failure and psychiatric aspects of immunosuppressant and anti-infectious agents. Psychosomatics 1993; 34: 199-207.

29. Miller BW, Brennan DC. Maintenance immunosuppressive therapy in renal transplantation in adults. ht tp:/ /patients.update.com/topic.asp?file $=$ renltran $/ 7721$ \&title=Diabetes \#references

30. Agha JA, Alvarez A, Lopez L, et al. Human polyoma virus infects a high proportion of renal Allograft recipients and the incidence is not affected by choice of calcineurin inhibitor. Gen Hosp Psych 1991; 13: 233245.

31. Solez K, Axelsen RA, Benediktsson H. International standardization of nomenclature and criteria for the histologic diagnosis of renal Allograft rejection: The Banff working classification of kidney transplant pathology. Kidney Int 1993;44(2):411-422.

32. Babcock H, Powell DH. Vasovagal fainting decoditioning: An autonomic syndrome. Psychosomatics 1982; 23: 969-973.

33. Surman OS, Cosimi AB, DuMartini A. Psychiatric care of patients undergoing organ transplantation. Transplantation 2009; 87: 1753-61.

34. Dubovsky S, Penn I. Psychiatric considerations in renal transplant surgery. Psychosomatics 1980; 21: 481-489.

35. Leo RJ, Smith BA, Mori L. Guidelines for conducting a psychiatric evaluation of the unrelated kidney donor. Psychosomatics 2003; 44: 452-460.

36. Gawande A. The checklist: if something so simple can transform intensive care, what else can it do?. New Yorker 2007;10: 86-101. 
Gaviria M. et al.

37. Satel S. Desperately seeking a kidney. The New York Times Magazine; December 16, 2007. http:// www.nytimes.com/2007/12/16/magazine/16kidneyt.html?_r=1.
38. Gitlin DF, Levenson JL, Lyketsos CG. Psychosomatic Medicine: A new psychiatric subspecialty. Academic Psychiatry, 2004; 28:4-11. 